\title{
Implementation of Temperature Sensor for LVCMOS25 Using Virtex6 FPGA
}

\author{
Nisha Pandey ${ }^{1}$, Shivani Sharma ${ }^{2}$, B S Chowdhary ${ }^{3}$, Amanpreet Kaur ${ }^{4}$, \\ Minal Dhankar ${ }^{5}$
}

${ }^{1}$ Bhim Rao Ambedkar Bihar University, Muzaffarpur, India

${ }^{2}$ Gyancity Research Lab, Gurgaon, India

${ }^{3}$ MUET, Jamshoro, Pakistan

${ }^{4}$ Chitkara University, Punjab, India

${ }^{5}$ Maharaja Surajmal Institute, New Delhi, India

nisha@gyancity.com, shivani.sharma@gyancity.com, c.bhawani@ieee.org, amanpreet.kaur@chitkara.edu.in, minal.dhankar@gmail.com

\begin{abstract}
Variation in temperature is a common phenomenon which can affect the performance factor of any device used at different temperatures. Temperature sensors are used to identify the variation in temperature at various or same places as temperature can vary according to time at same place also. This work is related to making Temperature sensor Design on Virtex6 Field Programmable Gate Array for Low Voltage Complementary Metal Oxide Semiconductor. Energy Consumption status at is taken care off for making the sensor low power and efficient. Xilinx is used for the same purpose. The idea is to make such sensors to measure temperature which itself does not affect from the changing heat content of environment.
\end{abstract}

Keywords- FPGA, Low Voltage Complementary Metal Oxide, Temperature Sensor.

\section{INTRODUCTION}

This paper is for enhancement in power consumption of a room temperature Sensor .Temperature Sensor is analyzed using VHDL. Interpretation is done using Xilinx and Virtex6 FPGA is used for LVCMOS25 standard .Value of output load is changed i.e. capacitance scaling [1] is done at particular frequency and change in Junction Temperature, Ambient Temperature, I/Os and ultimately total power is noticed. These temperatures are converted to Kelvin from degree Celsius for plotting data graphically. Same process is done for three different operating frequencies. The output load i.e. Capacitance which is in picoFarads is scaled from $10 \mathrm{pF}$ to $100 \mathrm{pF}$. Temperature is simply the measurement of how much heat content is present in that particular body. Temperature Sensors are used in many circuits as temperature variation is major factor which affects all circuits. It is not possible practically to measure the exact heat in a system. For measuring the content of heat following can be used as sensors as shown in figure1.
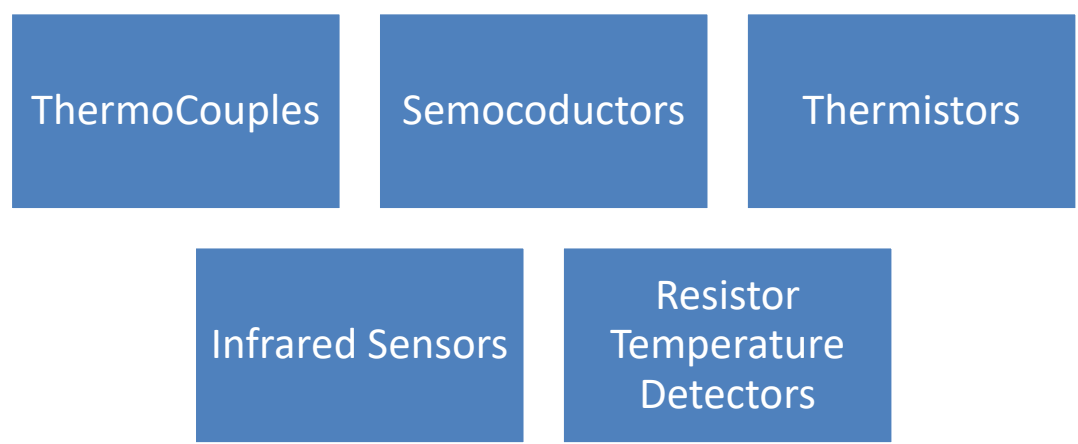

Resistor

Temperature

Detectors

Figure 1: Different Types of Temperature Sensors. 
Capacity of each depends upon the application of usage. Our Implementation is using Field Programmable Gate Array for particular type of Standard and hence measuring the factors responsible for performance of the temperature sensor. The schematic view of room temperature obtained from Xilinx ISE design Suite 12.1 is shown in Fig. 2.

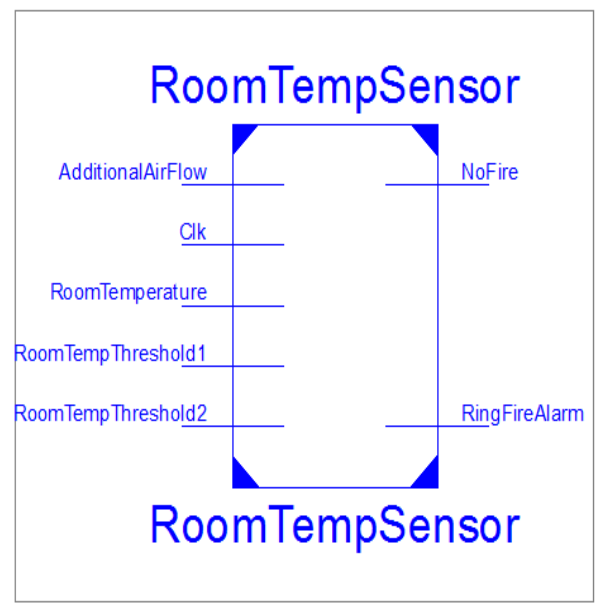

Figure 2: Schematic View Of Temperature Sensor

\section{RELATED WORK}

There are some projects which relate to the work in field of analyzing the temperature Sensors. This is requirement for sensing the temperature at different levels for accuracy in performance of electronic Circuits. The listed papers have done some work in this area.

1. Digital time-domain smart temperature sensor with 140 FPGA logic elements [2]

This paper proposed a smart temperature sensor design which is processed in time domain and implemented by Field Programmable Chips. It is a fully digital design in which current or voltage domains are not used .The whole idea goes around making the smart sensor for low power and low cost VLSI on-chip Integration. The measurement of power using capacitance scaling for different operating frequency is not done in this project which is been implemented by us.

\section{A low power all-digital self-calibrated temperature sensor using 65nm FPGAs [3]}

The technique used in this paper for power saving is by using hybrid counter without increasing area overhead. This is a delay line based temperature sensor. To generate digital representation and to reduce process variation self calibration methodology is used. Different approaches of energy saving are met in both papers. But the idea is same of making the sensor low power.

\section{Thermal aware Internet of Things Enable Energy Efficient Encoder on FPGA [4]}

The same approach using Xilinx is adopted by this paper. But this is used for design of an encoder. The software used is also Xilinx and the analysis is done for family of LVCMOS. Thermal and power analysis is done and also plotted graphically. Methodology used for research is almost same but the work is done in order to make Encoder design Efficient instead of temperature sensor. The design is made on FPGA as done in our paper.

\section{ReSEARCh Methodology}

The methodology adapted for our work uses Xilinx software. The code is written using VHDL. LVCMOS25 is set as a standard which is default and for three different operating frequencies i.e. $1 \mathrm{GHz}, 10 \mathrm{GHz}$ and $100 \mathrm{GHz}$ the value of output load is varied. The ambient temperature variation and junction temperature variation are noticed. Ultimately, the 
Gyancity Journal of Electronics and Computer Science,

Vol.1, No.1, pp. 6-12, September 2016

ISSN: 2446-2918 DOI: 10.21058/gjecs.2016.11002

percentage change in temperature, I/Os and total consumed power is obtained and data is analyzed graphically for precise and accurate interpretation.

\section{DATA ANALYSIS AND INTERPRETATION}

\section{A. Results on 1 GHz Operating Frequency}

Table 1: Total Power and Temperature with Output Load from $10-50$ at $1 \mathrm{GHz}$

\begin{tabular}{|l|l|l|l|l|l|}
\hline Output Load & 10 & 20 & 30 & 40 & 50 \\
\hline $\begin{array}{l}\text { Junction } \\
\text { Temperature }\end{array}$ & 52.3 & 52.4 & 52.4 & 52.4 & 52.4 \\
\hline $\begin{array}{l}\text { Ambient } \\
\text { Temperature }\end{array}$ & 82.7 & 82.6 & 82.6 & 82.6 & 82.6 \\
\hline IOs & 0.023 & 0.029 & 0.035 & 0.041 & 0.047 \\
\hline Total Power & 0.750 & 0.756 & 0.762 & 0.768 & 0.774 \\
\hline
\end{tabular}

There is negligible change in the junction temperature as well as ambient temperature when the output load is scaled from $10 \mathrm{pF}$ to $20 \mathrm{pF}, 30 \mathrm{pF}, 40 \mathrm{pF}$ and $50 \mathrm{pF}$ respectively. There is $12.76 \%, \%, 25.53 \%, 38.29 \%$ and $51.06 \%$ reduction in the IOs when we scale down output load from $50 \mathrm{pF}$ to $40 \mathrm{pF}, 30 \mathrm{pF}, 20 \mathrm{pF}$ and $10 \mathrm{pF}$ respectively. There is $.77 \%, \%, 1.55 \%$, $2.32 \%$ and $3.10 \%$ reduction in the total power when we scale down output load from $50 \mathrm{pF}$ to $40 \mathrm{pF}, 30 \mathrm{pF}, 20 \mathrm{pF}$ and $10 \mathrm{pF}$ respectively as shown in Fig. 3

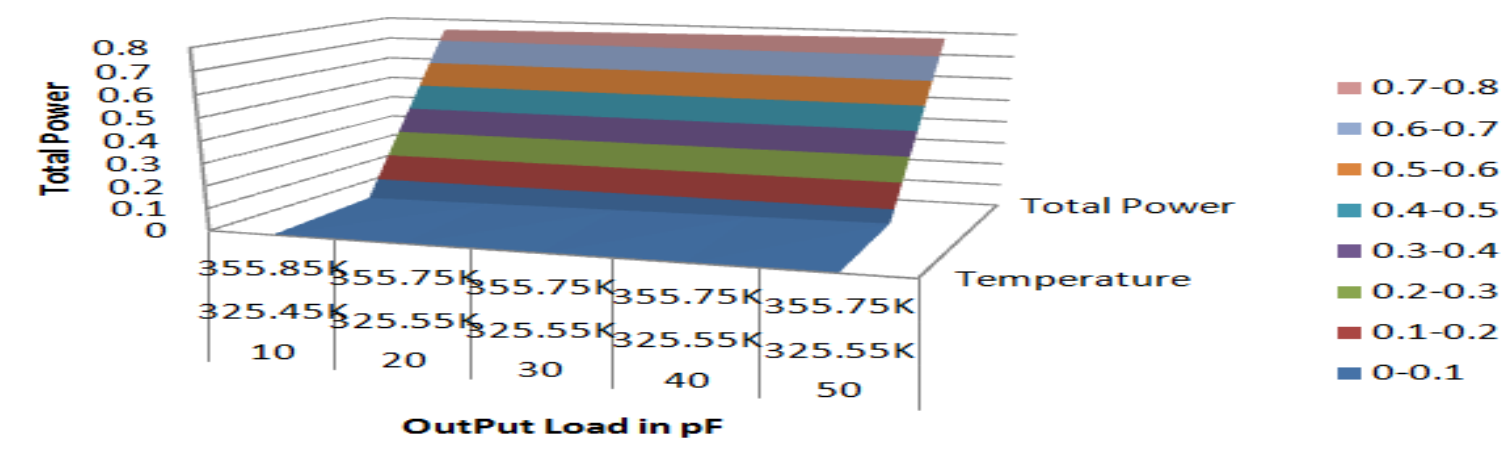

Figure3: Output Load from 10-50 with Temperature and Total Power at $1 \mathrm{GHz}$

Table2: Total Power and Temperature with Output Load from $60-100$ at $1 \mathrm{GHz}$

\begin{tabular}{|l|l|l|l|l|l|}
\hline Output Load & 60 & 70 & 80 & 90 & 100 \\
\hline $\begin{array}{l}\text { Junction } \\
\text { Temperature }\end{array}$ & 52.4 & 52.4 & 52.5 & 52.5 & 52.5 \\
\hline $\begin{array}{l}\text { Ambient } \\
\text { Temperature }\end{array}$ & 82.6 & 82.6 & 82.5 & 82.5 & 82.5 \\
\hline IOs & 0.053 & 0.059 & 0.065 & 0.071 & 0.077 \\
\hline Total Power & 0.780 & 0.786 & 0.792 & 0.799 & 0.805 \\
\hline
\end{tabular}

There is negligible change in the junction temperature as well as ambient temperature when the output load is scaled from $60 \mathrm{pF}$ to $70 \mathrm{pF}, 80 \mathrm{pF}, 90 \mathrm{pF}$ and $100 \mathrm{pF}$ respectively. There is $7.79 \%, \%, 15.58 \%, 23.37 \%$ and $31.16 \%$ reduction in the IOs when we scale down output load from $100 \mathrm{pF}$ to $90 \mathrm{pF}, 80 \mathrm{pF}, 70 \mathrm{pF}$ and $60 \mathrm{pF}$ respectively. There is .74\%, \%, 1.61\%, $2.36 \%$ and $3.10 \%$ reduction in the total power when we scale down output load from $100 \mathrm{pF}$ to $90 \mathrm{pF}, 80 \mathrm{pF}, 70 \mathrm{pF}$ and $60 \mathrm{pF}$ respectively as shown in Fig. 4. 
Gyancity Journal of Electronics and Computer Science,

Vol.1, No.1, pp. 6-12, September 2016

ISSN: 2446-2918 DOI: 10.21058/gjecs.2016.11002

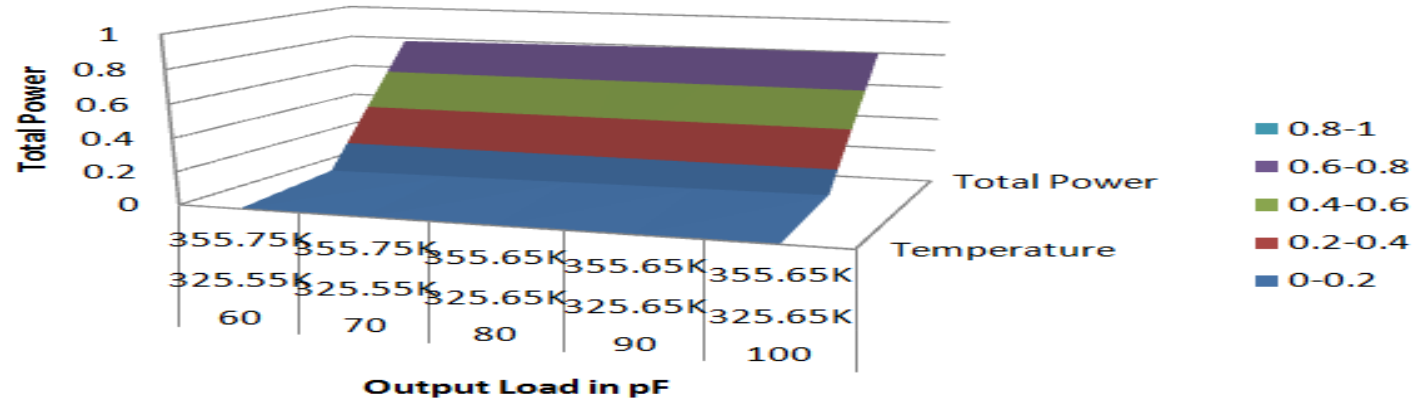

Figure4: Output Load from 60-100 with Temperature and Total Power at $1 \mathrm{GHz}$

\section{B. Results on $10 \mathrm{GHz}$ Operating frequency}

Table 3: Total Power and Temperature with Output Load from 10-50 at 10GHz

\begin{tabular}{|l|l|l|l|l|l|}
\hline Output Load & 10 & 20 & 30 & 40 & 50 \\
\hline $\begin{array}{l}\text { Junction } \\
\text { Temperature C }\end{array}$ & 53.3 & 53.5 & 53.7 & 53.9 & 54.1 \\
\hline $\begin{array}{l}\text { Ambient } \\
\text { Temperature C }\end{array}$ & 81.7 & 81.5 & 81.3 & 81.1 & 80.9 \\
\hline IOs & 0.233 & 0.292 & 0.352 & 0.411 & 0.471 \\
\hline Total Power & 1.091 & 1.152 & 1.213 & 1.274 & 1.335 \\
\hline
\end{tabular}

There is $.36 \%, .73 \%, 1.10 \%$ and $1.47 \%$ reduction in the junction temperature when the output load is scaled from $50 \mathrm{pF}$ to $40 \mathrm{pF}, 30 \mathrm{pF}, 20 \mathrm{pF}$ and $10 \mathrm{pF}$ respectively and also there is $0.24 \%$, $0.48 \%, 0.73 \%$ and $0.97 \%$ reduction in the total power when output load is scaled from $10 \mathrm{pF}$ to $20 \mathrm{pF}, 30 \mathrm{pF}, 40 \mathrm{pF}$ and $50 \mathrm{pF}$ respectively. There is $25.26 \%, \%, 38 \%, 50.53 \%$ and $12.95 \%$ reduction in the IOs when we scale down output load from $50 \mathrm{pF}$ to $40 \mathrm{pF}, 30 \mathrm{pF}, 20 \mathrm{pF}$ and $10 \mathrm{pF}$ respectively. There is $4.56 \%, 9.13 \%, \%, 13.70 \%$ and $18.27 \%$ reduction in the total power when we scale down output load from $50 \mathrm{pF}$ to $40 \mathrm{pF}, 30 \mathrm{pF}, 20 \mathrm{pF}$ and $10 \mathrm{pF}$ respectively as shown in Fig. 5.

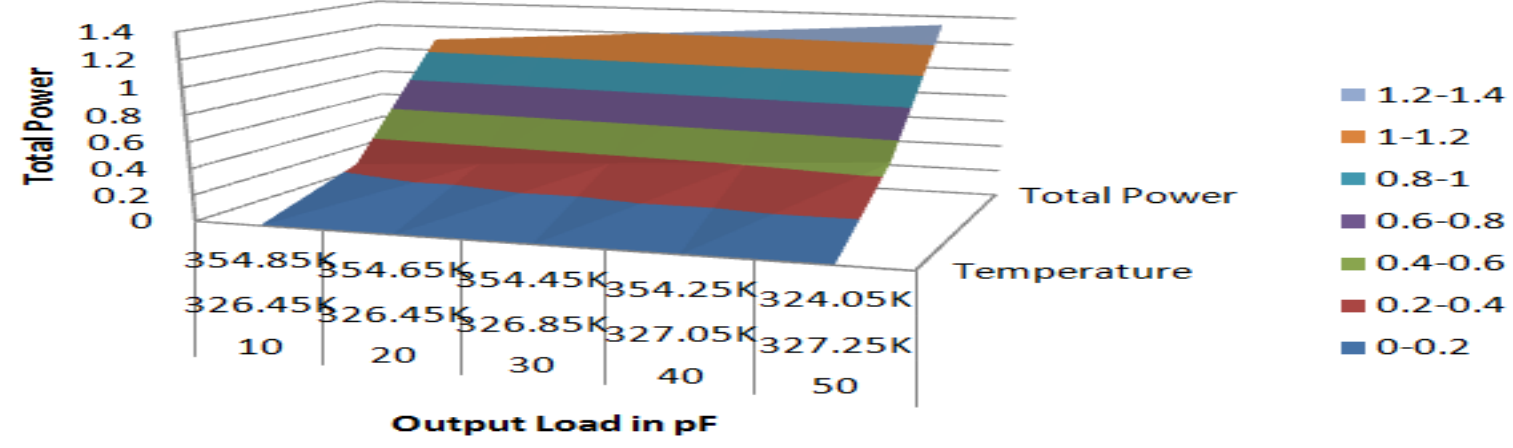

Fig. 5: Output Load from 10-50 with Temperature and Total Power at $1 \mathrm{GHz}$

Table 4: Total Power and Temperature with Output Load from $60-100$ at $10 \mathrm{GHz}$

\begin{tabular}{|l|l|l|l|l|l|}
\hline Output Load & 60 & 70 & 80 & 90 & 100 \\
\hline $\begin{array}{l}\text { Junction } \\
\text { Temperature }\end{array}$ & 54.2 & 54.4 & 54.6 & 54.8 & 55 \\
\hline $\begin{array}{l}\text { Ambient } \\
\text { Temperature }\end{array}$ & 80.8 & 80.6 & 80.4 & 80.2 & 80 \\
\hline IOs & 0.530 & 0.590 & 0.649 & 0.709 & 0.768 \\
\hline Total Power & 1.396 & 1.457 & 1.518 & 1.579 & 1.640 \\
\hline
\end{tabular}


There is $.36 \%, .72 \%, 1.09 \%$ and $1.45 \%$ reduction in the junction temperature when the output load is scaled from $100 \mathrm{pF}$ to $90 \mathrm{pF}, 80 \mathrm{pF}, 70 \mathrm{pF}$ and $60 \mathrm{pF}$ respectively and also there is $.24 \%$, $.49 \%, .74 \%$ and $.99 \%$ reduction in the total power when output load is scaled from $60 \mathrm{pF}$ to $70 \mathrm{pF}, 80 \mathrm{pF}, 90 \mathrm{pF}$ and $100 \mathrm{pF}$ respectively. There is $7.68 \%, \%, 15.49 \%, 23.17 \%$ and $30.98 \%$ reduction in the IOs when we scale down output load from $100 \mathrm{pF}$ to $90 \mathrm{pF}, 80 \mathrm{pF}, 70 \mathrm{pF}$ and $60 \mathrm{pF}$ respectively. There is $3.71 \%, \%, 7.439 \%, 11.15 \%$ and $14.87 \%$ reduction in the total power when we scale down output load from $100 \mathrm{pF}$ to $90 \mathrm{pF}, 80 \mathrm{pF}, 70 \mathrm{pF}$ and $60 \mathrm{pF}$ respectively as shown in Fig. 6.

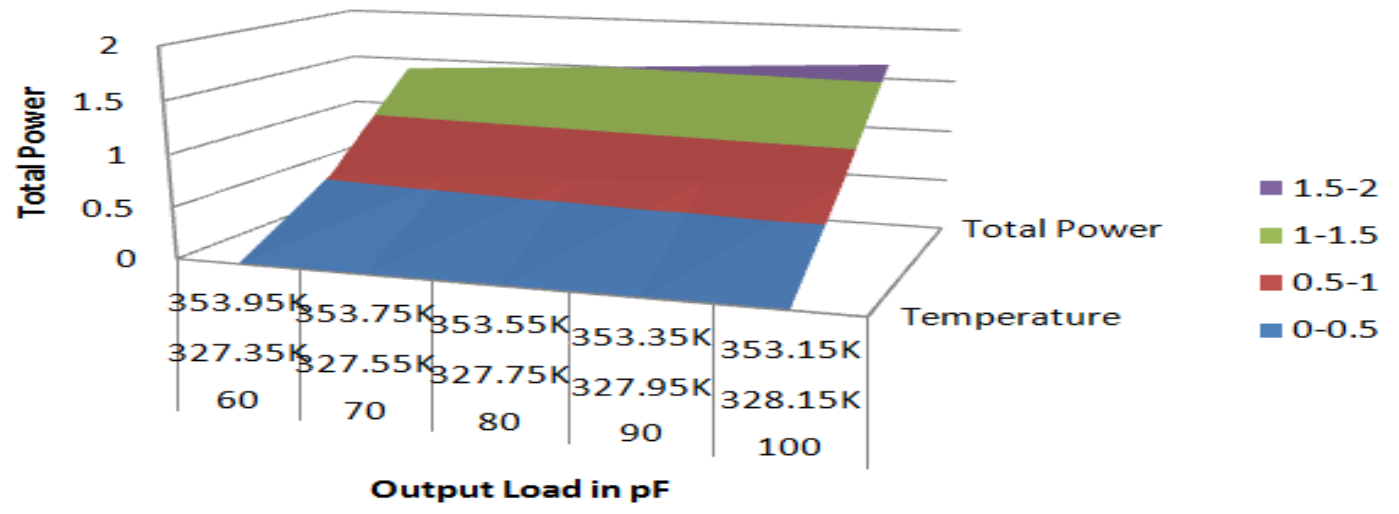

Figure 6: Output Load from 60-100 with Temperature and Total Power at 10GHz

\section{Results on $100 \mathrm{GHz}$}

Table 5: Total Power and Temperature with Output Load from 10-50 at 100GHz

\begin{tabular}{|l|l|l|l|l|l|}
\hline Output Load & 10 & 20 & 30 & 40 & 50 \\
\hline $\begin{array}{l}\text { Junction } \\
\text { Temperature }\end{array}$ & 63.4 & 65.2 & 67 & 68.8 & 70.7 \\
\hline $\begin{array}{l}\text { Ambient } \\
\text { Temperature }\end{array}$ & 71.6 & 69.8 & 68.0 & 66.2 & 64.3 \\
\hline IOs & 2.328 & 2.923 & 3.517 & 4.112 & 4.707 \\
\hline Total Power & 4.515 & 5.126 & 5.737 & 6.349 & 6.962 \\
\hline
\end{tabular}

There is $2.68 \%, 5.23 \%, 7.77 \%$ and $10.32 \%$ reduction in the junction temperature when the output load is scaled from $50 \mathrm{pF}$ to $40 \mathrm{pF}, 30 \mathrm{pF}, 20 \mathrm{pF}$ and $10 \mathrm{pF}$ respectively and also there is $2.51 \%, 5.02 \%, 7.54 \%$ and $10.19 \%$ reduction in the total power when output load is scaled from $10 \mathrm{pF}$ to $20 \mathrm{pF}, 30 \mathrm{pF}, 40 \mathrm{pF}$ and $50 \mathrm{pF}$ respectively. There is $12.6 \%, \%, 25.28 \%, 37.90 \%$ and $50.54 \%$ reduction in the IOs when we scale down output load from $50 \mathrm{pF}$ to $40 \mathrm{pF}$, $30 \mathrm{pF}, 20 \mathrm{pF}$ and $10 \mathrm{pF}$ respectively. There is $8.80 \%, \%, 17.59 \%, 26.37 \%$ and $35.14 \%$ reduction in the total power when we scale down output load from $50 \mathrm{pF}$ to $40 \mathrm{pF}, 30 \mathrm{pF}, 20$ $\mathrm{pF}$ and $10 \mathrm{pF}$ respectively as shown in Fig. 7.

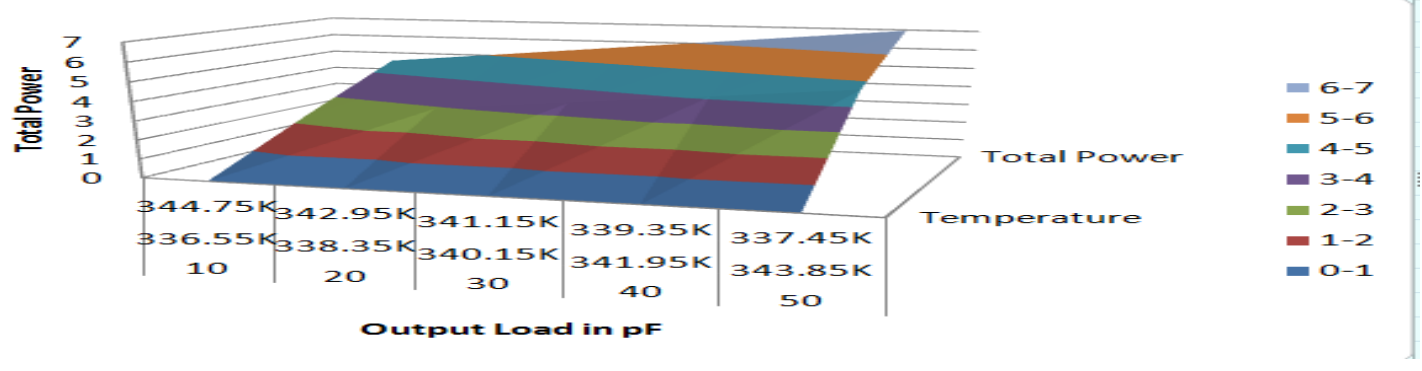

Figure 7: Output Load from 10-50 with Temperature and Total Power at 100GHz 
Gyancity Journal of Electronics and Computer Science, Vol.1, No.1, pp. 6-12, September 2016

ISSN: 2446-2918 DOI: 10.21058/gjecs.2016.11002

Table 6: Total Power and Temperature with Output Load from 60-100 at 10GHz

\begin{tabular}{|l|l|l|l|l|l|}
\hline Output Load & 60 & 70 & 80 & 90 & 100 \\
\hline $\begin{array}{l}\text { Junction } \\
\text { Temperature }\end{array}$ & 72.5 & 74.3 & 76.1 & 77.9 & 79.7 \\
\hline $\begin{array}{l}\text { Ambient } \\
\text { Temperature }\end{array}$ & 62.5 & 60.7 & 58.9 & 57.1 & 53.3 \\
\hline IOs & 5.301 & 5.896 & 6.491 & 7.086 & 7.680 \\
\hline Total Power & 7.575 & 8.188 & 8.801 & 9.415 & 10.030 \\
\hline
\end{tabular}

There is $2.25 \%, 4.51 \%, 6.77 \%$ and $9.03 \%$ reduction in the junction temperature when the output load is scaled from $100 \mathrm{pF}$ to $90 \mathrm{pF}, 80 \mathrm{pF}, 70 \mathrm{pF}$ and $60 \mathrm{pF}$ respectively and also there is $2.88 \%, 5.76 \%, 8.64 \%$ and $14.72 \%$ reduction in the total power when output load is scaled from $60 \mathrm{pF}$ to $70 \mathrm{pF}, 80 \mathrm{pF}, 90 \mathrm{pF}$ and $100 \mathrm{pF}$ respectively. There is $7.73 \%, \%, 15.48 \%, 23.22 \%$ and $30.97 \%$ reduction in the IOs when we scale down output load from $100 \mathrm{pF}$ to $90 \mathrm{pF}$, $80 \mathrm{pF}, 70 \mathrm{pF}$ and $60 \mathrm{pF}$ respectively. There is $6.13 \%, \%, 12.25 \%, 12.25 \%$ and $24.74 \%$ reduction in the total power when we scale down output load from $100 \mathrm{pF}$ to $90 \mathrm{pF}, 80 \mathrm{pF}, 70$ $\mathrm{pF}$ and $60 \mathrm{pF}$ respectively as shown in Fig. 8.

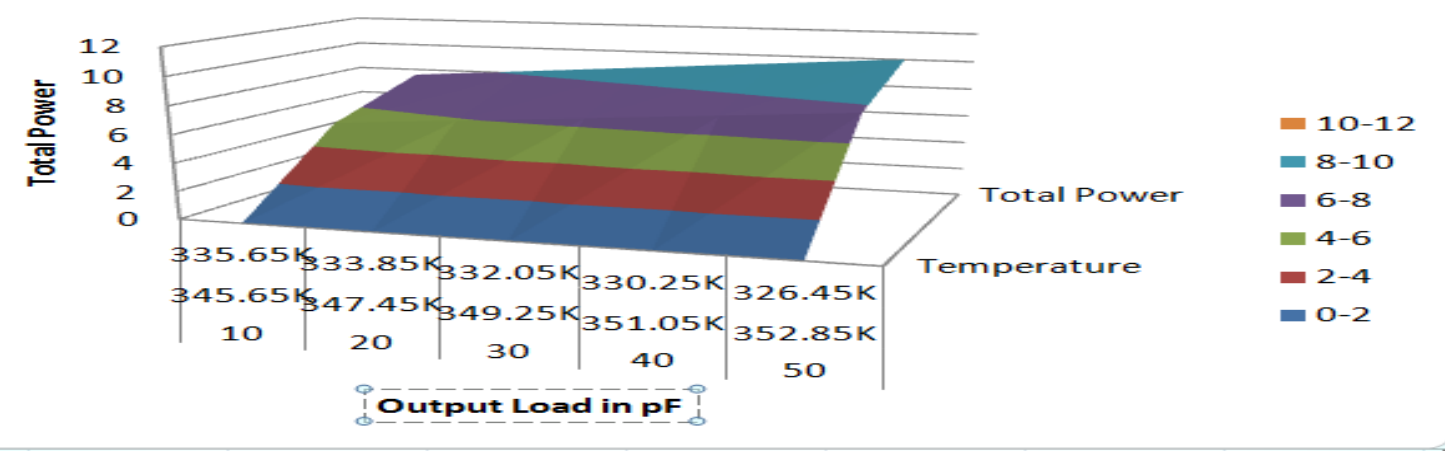

Figure 8: Variation of total power and temperature with output load at $0.1 \mathrm{GHz}$

\section{Conclusion}

The temperature sensor design is implemented using LVCMOS25 standard for three different frequencies i.e. $1 \mathrm{GHz}, 10 \mathrm{GHz}$ and $100 \mathrm{GHz}$. Virtex6 Field Programmable Array is used for fulfilling the requirements. The reduction in power at $1 \mathrm{GHz}$ is $.77 \%$ to $3.10 \%$ for $50 \mathrm{pF}-10 \mathrm{pF}$ output Load and $.74 \%$ to $3.10 \%$ for $100 \mathrm{pF}-60 \mathrm{pF}$ output Load. The reduction in power at $10 \mathrm{GHz}$ is $4.56 \%$ to $18.27 \%$ for $50 \mathrm{pF}-10 \mathrm{pF}$ output Load and $3.71 \%$ to $14.87 \%$ for $100 \mathrm{pF}-$ $60 \mathrm{pF}$ output Load and the maximum reduction in power at $100 \mathrm{GHz}$ is $8.80 \%$ to $35.14 \%$ for $50 \mathrm{pF}-10 \mathrm{pF}$ output Load and $6.13 \%$ to $24.74 \%$ for $100 \mathrm{pF}-60 \mathrm{pF}$ output Load. These are the results obtained from Xilinx software.

\section{Future ScOPE}

For making temperature sensor more efficient work is done for various standards other than default i.e. LVCMOS25 which is used in this paper. In future, temperature sensor can attain even lower power than this using other IO standards like SSTL, HSTL, LVDCI, HSUL, Mobile DDR, PCI, GTL etc. [5]. Capacitance scaling is used here. We can also use frequency scaling or voltage scaling for designing the same. In Further results can be obtained using Spartan6, Kintex-7, Artix-7and Virtex7. 


\section{REFERENCES}

[1] S. Hyder Abbas Musavi, B. S. Chowdhry, T. Kumar, B. Pandey, W. Kumar, "IoTs Enable Active Contour Modeling Based Energy Efficient and Thermal Aware Object Tracking on FPGA", Wireless Personal Communications, Volume 85, No.2, pp.529-543, 20 May 2015,

[2] Chen, P., Shie, M. C., Zheng, Z. Y., Zheng, Z. F., \& Chu, C. Y. " A fully digital time-domain smart temperature sensor realized with 140 FPGA logic elements."IEEE Transactions on Circuits and Systems I: Regular Papers, 54(12), 2661-2668.

[3] Xie, S., \& Ng, W. T. A low power all-digital self-calibrated temperature sensor using 65nm FPGAs. In Circuits and Systems , International Symposium on (pp. 2617-2620). IEEE

[4] D. Singh, K. Garg, R. Singh, B. Pandey, K.Kalia, and H. Noori. "Thermal aware Internet of Things Enable Energy Efficient Encoder Design for security on FPGA." International Journal of Security and Its Applications 9, no. 6, June 2015, Page: 271-278

[5] B. Pandey, V. Thind, S. K. Sandhu, T. Walia, and S. Sharma. "SSTL Based Power Efficient Implementation of DES Security Algorithm on 28nm FPGA." International Journal of Security and Its Application 9, no. 7, July 2015, Page: 267-274. 